\title{
Selenium Oxyanion Uptake on Iron Oxides and Pyroaurites: Probing Mechanisms Using ${ }^{18} \mathrm{O}$ Tracing
}

\author{
P. LARESE-CASANOVA ${ }^{1 *}$, P. YUE ${ }^{1}$, A.E.P. \\ SCHELlENGER $^{1}$, N. CHEN $^{2}$, D. PEAK. ${ }^{3}$, N.M. BOMPOTI ${ }^{4}$, \\ M. CHRYSOCHOOU ${ }^{4}$, A. ONNIS-HAYDEN ${ }^{1}$
}

${ }^{1}$ Dept. of Civil \& Environmental Engineering, Northeastern University, Boston, MA, USA (*correspondance: p.laresecasanova@northeastern.edu

${ }^{2}$ Canadian Light Source, University of Saskatchewan, Saskatoon, SK, Canada

${ }^{3}$ Dept. of Soil Science, University of Saskatchewan, Saskatoon, SK, Canada

${ }^{4}$ Dept. of Civil \& Environmental Engineering, University of Connecticut, Storrs, CT, USA

Selenite was observed to form inner-sphere bidentate complexes, and selenate to form outer-sphere complexes, on both goethite and hematite at acidic and circumneutral $\mathrm{pH}$. Inner-sphere bidentate selenite complex formation requires release of two $\mathrm{O}$, and by tracing ${ }^{18} \mathrm{O}$ release from ${ }^{18} \mathrm{O}$ enriched oxides to isotopically normal water, it was found that $\mathrm{O}$ release from the oxide surface accounted for $22 \%$ and $7 \%$ of total adsorption-induced $\mathrm{O}$ release for goethite and hematite, respectively, but only at $\mathrm{pH}$ 3.0. Considering surface complexation modeling and $\mathrm{H}^{+}$coadsorption data, a stepwise process is proposed where the first of two Se-O-Fe bonds causes oxide-O to be released from a $=\mathrm{Fe}-\mathrm{OH}_{2}{ }^{+0.5}$ site, but only at low Se coverages. The remaining $\mathrm{O}$ release is assumed to be from adsorbed selenite itself. Selenate with enriched goethite and hematite at $\mathrm{pH} 3.0$ also induced a slight increase in ${ }^{18} \mathrm{O}$ enrichment in bulk $\mathrm{H}_{2} \mathrm{O}$, which is unexpected for selenate's outer-sphere configuration that should produce no $\mathrm{O}$ ligand exchange, but instead suggests some spontaneous adsorption-induced oxide $\mathrm{O}$ release.

Selenate and selenite uptake with pyroaurites and green rusts occurred by interlayer anion exchange. Uptake extents were controlled by the identity of the interlayer anion according to the order $\mathrm{Cl}^{-}>\mathrm{SO}_{4}{ }^{2-}>\mathrm{CO}_{3}{ }^{2-}$. For the pyroaurites, the kinetics of Se uptake typically followed a biphasic behavior with a rapid initial anion exchange step followed by a slow re-exchange back to solution due to competition with expelled interlayer anions. Excess dissolved interlayer anions and high $\mathrm{pH}$ values exacerbated this reverse exchange of Se, suggesting Se oxyanions taken up by pyroaurites may not be firmly sequestered. However, in the absence of external competing anions, selenate appears to not cycle itself in and out of the Cl-pyroaurite interlayer spontaneously and remain fixed, as revealed by ${ }^{18} \mathrm{O}$-selenate tracing. 